\title{
Meeting Air Transportation Demand in 2025 by using Larger Aircraft and Alternative Routing to Complement NextGen Operational Improvements
}

\author{
Jeremy C. Smith ${ }^{1}$ \\ NASA Langley Research Center, Hampton, VA, 23681-2199 \\ and \\ Nelson M. Guerreiro² \\ ATK Space Systems, Inc., Hampton, VA, 23681-2199 \\ with assistance from \\ Jeffrey K. Viken ${ }^{3}$ \\ NASA Langley Research Center, Hampton, VA, 23681-2199 \\ Samuel M. Dollyhigh ${ }^{4}$ and James W. Fenbert ${ }^{5}$ \\ ATK Space Systems, Inc., Hampton, VA, 23681-2199
}

\begin{abstract}
A study was performed that investigates the use of larger aircraft and alternative routing to complement the capacity benefits expected from the Next Generation Air Transportation System (NextGen) in 2025. National Airspace System (NAS) delays for the 2025 demand projected by the Transportation Systems Analysis Models (TSAM) were assessed using NASA's Airspace Concept Evaluation System (ACES). The shift in demand from commercial airline to automobile and from one airline route to another was investigated by adding the route delays determined from the ACES simulation to the travel times used in the TSAM and re-generating new flight scenarios. The ACES simulation results from this study determined that NextGen Operational Improvements alone do not provide sufficient airport capacity to meet the projected demand for passenger air travel in 2025 without significant system delays. Using larger aircraft with more seats on high-demand routes and introducing new direct routes, where demand warrants, significantly reduces delays, complementing NextGen improvements. Another significant finding of this study is that the adaptive behavior of passengers to avoid congested airline-routes is an important factor when projecting demand for transportation systems. Passengers will choose an alternative mode of transportation or alternative airline routes to avoid congested routes, thereby reducing delays to acceptable levels for the 2025 scenario; the penalty being that alternative routes and the option to drive increases overall trip time by $0.4 \%$ and may be less convenient than the first-choice route.
\end{abstract}

\section{Introduction}

$\mathrm{T}$ HIS paper presents the results from a study that investigates the use of larger aircraft with more seats and alternative routing to complement the capacity benefits expected from the Next Generation Air Transportation System (NextGen) planned for 2025. The year 2025 is the Joint Planning and Development Office (JPDO) target year for implementation of NextGen as defined in the Concept of Operations ${ }^{[1]}$ (CONOPS).

\footnotetext{
${ }^{1}$ Senior Analyst, Aeronautics Systems Analysis Branch, Mail Stop 442, member AIAA.

${ }^{2}$ Research Engineer, Aeronautics Systems Analysis Branch, Mail Stop 442, member AIAA.

${ }^{3}$ Senior Analyst, Aeronautics Systems Analysis Branch, Mail Stop 442, member AIAA.

${ }^{4}$ Research Engineer, Aeronautics Systems Analysis Branch, Mail Stop 442, member AIAA.

${ }^{5}$ Research Engineer, Aeronautics Systems Analysis Branch, Mail Stop 442.
} 
The JPDO and the Federal Aviation Administration (FAA) have planned a series of Operational Improvements $^{[2]}$ (OIs) that will implement the JPDO CONOPS for NextGen. The OIs provide efficiency gains, increase the capacity of airspace, and increase throughput at the nation's airports with the objective of safely accommodating the projected increase in demand for air travel.

Demand projections for air transportation predict substantial increases by 2025, despite recent economic setbacks and the increased cost of jet fuel. The increase in passenger enplanements projected by 2025 at U.S. airports is about 1.4 times 2006 levels, according to the FAA's Terminal Area Forecast published in $2009^{[3]}$. An alternative forecast using the Transportation Systems Analysis Model ${ }^{[4]}$ (TSAM), predicts a higher growth in passenger enplanements of around 1.7 times 2006 levels. The difference between TSAM and the FAA forecast can be explained by the different assumptions and fidelities used in each of these models. The scheduled flight scenarios used in this study make use of TSAM projections.

TSAM is a demand prediction model under development by Virginia Polytechnic Institute's Air Transportation Systems Laboratory and NASA Langley Research Center. TSAM uses socio-economic and demographic modeling to make projections of future travel demand. The demand model uses the Woods and Poole Complete Economic and Demographic Data Source ${ }^{[5]}$, which is a socio-economic forecast of U.S. household demographics out to the year 2040.

TSAM predicts the total long distance (greater than 100 miles) passenger trips in the U.S. and allocates each of these to modes of transportation. For this study, the available modes are commercial airline and automobile, but future work may include rail as an alternative. TSAM also determines the origin and destination airport choices for the commercial airline mode in a mode-choice model, and determines the distribution of passengers amongst the possible network routes in an origin-transfer-destination model, thereby providing route-level and airport-level demand projections. Other data sources used to validate and calibrate the TSAM model include the 1995 American Travel Survey ${ }^{[6]}$ (ATS), the Official Airline Guide ${ }^{[7]}(\mathrm{OAG})$, and the Airline Origin and Destination Survey $(\mathrm{DB} 1 \mathrm{~B})^{[8]}$.

TSAM takes into account expected reductions in air-transportation travel times due to NextGen improvements. JPDO has stated a timesaving goal of $30 \%$ from airport curb-to-curb for its NextGen initiatives. This large reduction may be achievable by reducing flight times by a small factor, with the bulk of the savings coming from a reduction in airport processing time. A 5\% reduction in total flight time and a reduction in airport processing time, depending on airport size, are assumed for this study. A reduction in travel time increases demand for air transportation, particularly for the shorter flights where the alternative is to travel by automobile.

This study uses NASA's Airspace Concept Evaluation System ${ }^{[9]}$ (ACES) to assess National Airspace System (NAS) delays for the 2025 demand projected by TSAM. ACES represents the estimated capacity benefits expected in the year 2025 by increasing sector and airport capacities limits. The 2025 airport capacity values used in simulations include the benefits of additional runways and other improvements documented in the FAA's 2018 NextGen Implementation Plan (NGIP) plus the expected benefits from 2025 NextGen OIs.

\section{Motivation/ Significance}

The motivation for this study is to determine if using larger aircraft with more seats and alternative routing can complement the NextGen OIs and produce a transportation system that meets the projected demand under good weather conditions.

Using larger aircraft with more seats on congested routes reduces the number of operations required to meet the passenger demand, while making efficient use of available airspace and airport capacity. A frequency of service that is acceptable to passengers is important; this study analyzes existing airline schedules to ensure that future schedules maintain a number of daily flights comparable to today's scheduled operations. As demand increases, airlines may introduce new direct routes between city pairs that currently require a connection through a hub airport. This study introduces new routes that offload some traffic from hubs.

The key question that this study seeks to answer is -

Can NextGen capacity improvements, complemented by using larger aircraft with more seats and new direct routes accommodate the projected passenger demand in 2025 under good weather conditions?

A secondary question that this study seeks to answer is - 
If air transportation delays are excessive on some routes, are there alternative routes or modes of transportation available that can transport a portion of the passengers and reduce delays to acceptable levels?

The significance of the results presented in this paper is that with the expected improvements in airport capacity, NextGen improvements are unlikely to meet projected demand at all airports; even so, a viable air transportation system with acceptable delays is feasible. The use of larger aircraft with more seats on some high demand routes, introducing new direct routes where demand warrants, and taking into account the adaptive nature of the system, can achieve improved capacity and reduce delays. Passengers will choose less congested routes where viable alternatives exist or avoid air transportation on shorter trips, where ground transportation may be a feasible option. For this study, automobile is the only alternative mode modeled.

\section{Technical Approach}

The approach taken in this study is to use ACES NAS-wide simulation delays to effect passenger route and mode of transportation choices in TSAM. TSAM demand projections are used to create future flight scenarios using different assumptions, such as larger aircraft with more seats and new direct routes. ACES NAS-wide simulations determine the delays on each airport-pair route in the U.S. for each of these scenarios. The airline-route delays are then added to the nominal travel-times used in TSAM, creating a new demand projection. A further simulation then determines the remaining delays for this adjusted travel time scenario.

Delays are analyzed for each hour of the simulation; the mean and 95th percentile of gate-to-gate delay are the metrics used as recommended for NASA's Airspace System Program ${ }^{[10]}$ (ASP) system-wide studies.

The focus of this study is air travel and an equivalent study that accounts for automobile congestion has not been performed. The automobile driving times and costs presented to travelers within TSAM are the same for 2006 and 2025.

\section{Simulation Setup}

This study uses NASA's ACES Version 6.0. ACES is a fast time, distributed, agent-based simulation of the National Airspace System (NAS). ACES has models of airports, airspace, aircraft performance, basic traffic flow management and other elements of the NAS. ACES determines delay at various stages of flight by comparing the trajectory flown in simulation with a computed unimpeded trajectory. Total delay for each flight is the difference between actual gate arrival time in the simulation and the calculated unimpeded gate arrival time.

ACES models the airport and airspace capacity constraints of the NAS. The departure, arrival and total operations per hour rates set the airport capacities. Table 1 shows the airport capacities for 2006 and 2025 calculated by the NASA ASP for the FAA's Operational Evolution Plan (OEP) 35 airports. The OEP 35 airports are those considered by the FAA to have significant activity, and they comprise greater than $70 \%$ of the operations in the NAS. Table 1 shows the maximum number of arrivals, the maximum number of departures, and the maximum total number of operations (a mix of arrivals and departures for the most common airport configuration) for 2006 and 2025. The 2006 capacities are estimates of the actual values in the baseline year. An analysis of the 2018 FAA NGIP, plus additional benefits expected from NextGen OIs, determines the 2025 values.

An analysis of the FAA 2018 Plan by Optimal Synthesis Inc. estimated the airport capacity improvements due to NGIP ${ }^{[11]}$. The JPDO Systems Modeling and Analysis Division (SMAD) performed a bottom-up analysis of OIs to estimate capacity benefits for use by a NASA sponsored study of advanced vehicle concepts for NextGen ${ }^{[12]}$.

The future NAS is expected to increasingly rely on automation for conflict detection and resolution advisories, which has the potential to significantly increase airspace sector capacities. Airspace sector capacities in present day operations are derived from the ability of a human air traffic controller to handle a limited set of aircraft at any one time. SMAD estimated 2025 airspace sector capacities (or Monitor Alert Parameter (MAP) values) to be 1.95 times current values for congested sectors and 1.7 times current values for other sectors. For the purposes of simulating the increased sector capacities that may develop as a result of automated advisories, the ACES simulated sector capacities are set to twice current day capacities.

All results presented in this study assume Visual Meteorological Conditions (VMC) in the simulation of the NAS (i.e. a clear weather day). 
Table 1. ACES Assumed Capacities for 2025 OEP-35 Airports

\begin{tabular}{|c|c|c|c|c|c|c|c|}
\hline \multirow[b]{2}{*}{ Operational Evolution Plan (OEP) Airport } & \multicolumn{3}{|c|}{2006} & \multicolumn{3}{|c|}{2025} & \multirow{2}{*}{$\begin{array}{l}\text { Total \% } \\
\text { Increase }\end{array}$} \\
\hline & Dep. & Arr. & Tot. & Dep. & Arr. & Tot. & \\
\hline 1. ATL - Hartsfield-Jacks. Atlanta Intl. & 104 & 103 & 200 & 168 & 153 & 296 & $48 \%$ \\
\hline 2. BOS - Boston Logan Intl. & 100 & 75 & 131 & 114 & 85 & 165 & $26 \%$ \\
\hline 3. BWI - Baltimore/Washington Intl. & 83 & 63 & 108 & 121 & 94 & 195 & $81 \%$ \\
\hline 4. CLE - Cleveland Hopkins Intl. & 107 & 65 & 116 & 119 & 72 & 139 & $20 \%$ \\
\hline 5. CLT - Charlotte Douglas Intl. & 106 & 72 & 130 & 150 & 99 & 226 & $74 \%$ \\
\hline 6. CVG - Cincinnati/North Kty Intl. & 129 & 126 & 167 & 149 & 142 & 210 & $26 \%$ \\
\hline 7. DCA - Ronald Reagan Wash. Nat. & 56 & 44 & 88 & 63 & 50 & 110 & $25 \%$ \\
\hline 8. DEN - Denver Intl. & 142 & 124 & 266 & 169 & 147 & 315 & $18 \%$ \\
\hline 9. DFW - Dallas/Fort Worth Intl. & 113 & 166 & 279 & 138 & 205 & 343 & $23 \%$ \\
\hline 10. DTW - Detroit Metro Wayne & 100 & 123 & 195 & 111 & 136 & 233 & $19 \%$ \\
\hline 11. EWR - Newark Liberty Intl. & 53 & 47 & 91 & 59 & 53 & 110 & $21 \%$ \\
\hline 12. FLL - Fort Lauderdale Intl. & 65 & 64 & 86 & 86 & 83 & 133 & $55 \%$ \\
\hline 13. HNL - Honolulu Intl. & 32 & 31 & 55 & 32 & 31 & 55 & $0 \%$ \\
\hline 14. IAD - Washington Dulles Intl. & 101 & 121 & 134 & 113 & 135 & 161 & $20 \%$ \\
\hline 15. IAH - George Bush Houston & 119 & 107 & 198 & 133 & 119 & 237 & $20 \%$ \\
\hline 16. JFK - NY John F. Kennedy Intl. & 77 & 55 & 86 & 98 & 72 & 124 & $44 \%$ \\
\hline 17. LAS - Las Vegas McCarran Intl. & 49 & 42 & 77 & 57 & 49 & 100 & $30 \%$ \\
\hline 18. LAX - Los Angeles Intl. & 86 & 78 & 164 & 101 & 92 & 193 & $18 \%$ \\
\hline 19. LGA - New York LaGuardia & 49 & 42 & 77 & 57 & 49 & 100 & $30 \%$ \\
\hline 20. MCO - Orlando Intl. & 186 & 155 & 225 & 211 & 178 & 281 & $25 \%$ \\
\hline 21. MDW - Chicago Midway & 54 & 33 & 69 & 74 & 45 & 116 & $68 \%$ \\
\hline 22. MEM - Memphis Intl. & 100 & 114 & 181 & 115 & 132 & 231 & $28 \%$ \\
\hline 23. MIA - Miami Intl. & 88 & 76 & 146 & 102 & 88 & 180 & $23 \%$ \\
\hline 24. MSP - Minneapolis/St. Paul Intl. & 146 & 126 & 160 & 166 & 143 & 198 & $24 \%$ \\
\hline 25. ORD - Chicago O`Hare Intl. & 142 & 102 & 185 & 210 & 151 & 344 & $86 \%$ \\
\hline 26. PDX - Portland Intl. & 94 & 81 & 118 & 109 & 94 & 152 & $29 \%$ \\
\hline 27. PHL - Philadelphia Intl. & 68 & 57 & 97 & 79 & 68 & 127 & $31 \%$ \\
\hline 28. PHX - Phoenix Sky Harbor Intl. & 103 & 86 & 152 & 114 & 95 & 183 & $20 \%$ \\
\hline 29. PIT - Pittsburgh Intl. & 102 & 85 & 152 & 117 & 97 & 186 & $22 \%$ \\
\hline 30. SAN - San Diego Intl. & 52 & 42 & 58 & 58 & 46 & 70 & $21 \%$ \\
\hline 31. SEA - Seattle/Tacoma Intl. & 72 & 63 & 84 & 134 & 115 & 203 & $142 \%$ \\
\hline 32. SFO - San Francisco Intl. & 71 & 62 & 105 & 89 & 77 & 152 & $45 \%$ \\
\hline 33. SLC - Salt Lake City Intl. & 114 & 92 & 133 & 141 & 117 & 191 & $44 \%$ \\
\hline 34. STL - Lambert Saint Louis Intl. & 101 & 85 & 151 & 114 & 97 & 189 & $25 \%$ \\
\hline 35. TPA - Tampa Intl. & 62 & 81 & 104 & 85 & 112 & 172 & $65 \%$ \\
\hline
\end{tabular}

\section{Flight Data Sets}

ACES requires a Flight Data Set (FDS) input file that defines the flight schedule, i.e. departure airport and time, arrival airport and time; route of flight, cruise altitude and speed for each flight. Table 2 lists the six flight data sets used for this study, the total number of flights in each FDS file, the Commercial passenger flights only, and their ratios to the 2006 baseline scenario. The FDS file includes Commercial Domestic, Commercial International, Cargo, and General Aviation IFR flights. The basis for the FDS is a day of recorded traffic from the FAAs Enhanced Traffic Management System (ETMS) and is represented by the 2006 baseline FDS. The other FDS scenarios developed from the baseline with the TSAM demand projections use the NextGen OIs and the new routes and flight consolidation schemes. For this study a high volume good weather day, 26 September 2006, is the baseline day ${ }^{[13]}$.

TSAM projected demand growth for each airport-to-airport route is used to scale up the baseline to the 2025 schedules. The future schedules preserve the overall time-of-day distribution of flights in the 2006 data and introduce variations around the original departure times to ensure some spreading out of the schedule..

The 2025 max-operations FDS - built from simple growth scaling - implements a direct scaling of the TSAM route demand growths, i.e. a ratio of the 2006 to 2025 enplanements for each route, translated into aircraft operations using the same size aircraft and routes. The max-operations scenario is not realistic; airlines are unlikely to continue using similar sized aircraft and a similar route structure as that in use today, to meet the substantially increased demand projected for 2025. The max-operations scenario is useful for comparison with other 2025 scenarios. The other 2025 scenarios include the following refinements to represent a more realistic future projection. 
Table 2. ACES Flight Data Sets

\begin{tabular}{|c|c|c|c|c|}
\hline Flight Data Set & $\begin{array}{c}\text { All } \\
\text { Flights }\end{array}$ & $\begin{array}{l}\text { Ratio to } 2006 \\
\text { baseline }\end{array}$ & $\begin{array}{c}\text { Commercial } \\
\text { Passenger Flights } \\
\end{array}$ & $\begin{array}{c}\text { Ratio to } 2006 \\
\text { baseline }\end{array}$ \\
\hline 2006 baseline & 49670 & - & 29133 & - \\
\hline 2025 max-operations & 81878 & 1.65 & 54686 & 1.88 \\
\hline $\begin{array}{l}2025 \text { larger aircraft, } 40 \text { per day schedule limit, new direct } \\
\text { routes }\end{array}$ & 76063 & 1.53 & 49434 & 1.70 \\
\hline $\begin{array}{l}2025 \text { larger aircraft, } 20 \text { per day schedule limit, new direct } \\
\text { routes }\end{array}$ & 75795 & 1.53 & 48673 & 1.67 \\
\hline $\begin{array}{l}2025 \text { larger aircraft, } 20 \text { per day schedule limit, new direct } \\
\text { routes, congested route delays }\end{array}$ & 75208 & 1.51 & 48578 & 1.67 \\
\hline
\end{tabular}

On high demand routes, in addition to increasing the number of flights, the airlines may use larger aircraft with more seats to accommodate the increased number of passengers. With sufficient demand, airlines may create new direct routes between city pairs where there are no direct flights today. Using larger aircraft and direct routing reduces the number of flight operations required to transport the same number of passengers. The final scenario includes the effects of increased travel times on congested routes by adding the amount of delay obtained from simulation results.

The effects of the refinements made to the scenarios results in the reduced numbers of flights shown in Table 2. The number of projected flights in the year 2025 reduces by 5252 (9.6\%) for the 40 schedule frequency-limit scenario and by $6013(11.0 \%)$ for the 20 schedule frequency-limit scenario compared to the max-operations scenario. The reduction in operations occurs mainly on high demand routes.

Increasing travel times on congested routes makes very little difference to the overall reduction in the number of flights $6108(11.2 \%)$, which is an additional reduction of $95(0.2 \%)$ compared to the 20 schedule frequency-limit scenario without delays.

\section{A. Basis for the Introduction of Larger Aircraft and Direct Routes}

The Global Management Forecast ${ }^{[14]}$ from Airbus S.A.S. for 2005 to 2024, published the results of research that shows how airlines use a balance between more flights per day and larger aircraft with more seats to meet demand. For short routes, the schedule frequency is higher than for longer routes where airlines typically use large aircraft.

This study uses scenarios with a 20 or 40 flights per day schedule limit for all routes, to create realistic Flight Data Sets that bracket the likely range of maximum schedule frequency in the U.S. in 2025. The 20 and 40 aircraft per day schedule limit FDS, consolidates passengers from two or more smaller aircraft into larger aircraft as the schedule frequency increases. This reduces the number of flight operations on high demand routes, compared to the max-operations scenario.

Table 3 shows the number of departures on 26 September 2006 for the routes with the most flights. The maximum number of departures was 37 on the short trip from Seattle to Portland. The carriers for this route are Horizon Air and SkyWest using turbo-props. Longer routes have a lower frequency of service and use larger jet aircraft.

Table 3. Number of departures per day for top-10 routes on 9/26/2006

\begin{tabular}{ccc}
\hline Departure Airport & Arrival Airport & Departures Per Day \\
\hline \hline SEA & PDX & 37 \\
LAX & LAS & 35 \\
LAX & SAN & 35 \\
BOS & LGA & 34 \\
DCA & LGA & 34 \\
LGA & ORD & 34 \\
LAX & SFO & 33 \\
LAS & PHX & 30 \\
DFW & ATL & 28 \\
\hline
\end{tabular}

In addition to introducing larger aircraft, the scenarios take into account demand increases to drive the introduction of new routes. A direct route between city pairs removes passengers from the corresponding connecting routes. For this study, the criteria for new routes are that the demand is sufficient to justify two flights a day in a regional-jet-sized aircraft and that the airports already have commercial passenger service. 


\section{Results and Discussion}

The results presented in this section are from NAS-wide simulations of 27 hours of flight operations; that is 24 hours plus an additional 3 hours to account for the time zone difference across the U.S. All the results assume ideal conditions, with VMC airport capacities and airspace sector capacities as described in the "Simulation Setup" section.

\section{A. 2006 Baseline Delays}

The purpose of simulating baseline-day traffic is to check that ACES results are comparable to actual delays on a good-weather day in the NAS. This simulation uses 2006 airport capacities, see Table 1. Sector capacities are set to 2006 MAP values.

Figure 1 shows simulation results from ACES, for the 2006 baseline day scenario.

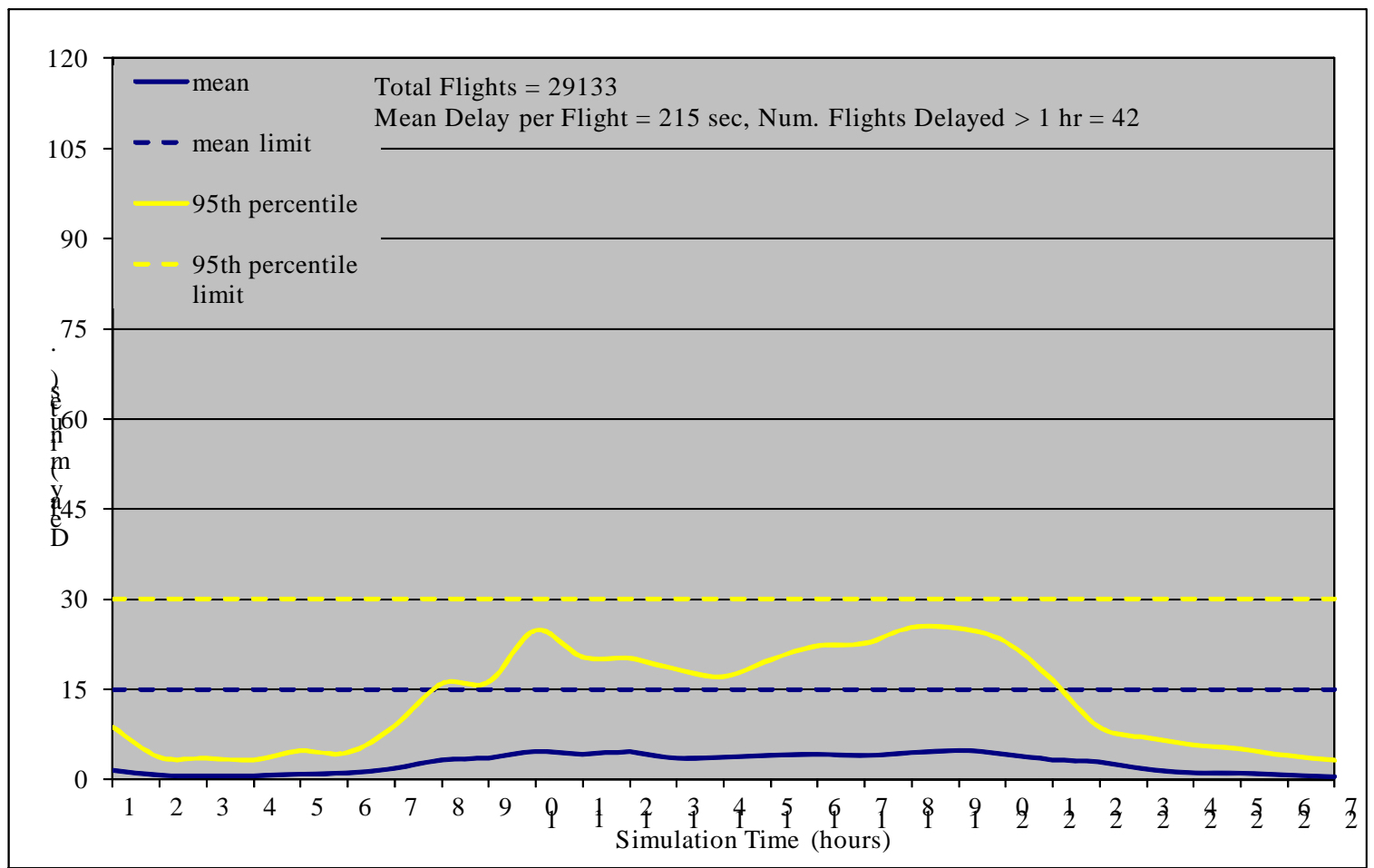

Figure 1. Commercial Passenger Flight Delays for 2006 Baseline Scenario

The chart shows the mean and $95^{\text {th }}$-percentiles of delay for each hour of simulation time for commercial passenger flights, compared to acceptable limits. For the purposes of this study, based on suggested ASP metrics ${ }^{[10]}$, a mean delay of 15 minutes or a $95^{\text {th }}$-percentile of delay that exceeds 30 minutes during any hour of the simulation is the acceptable limit. (The $95^{\text {th }}$-percentile is a more sensitive indicator of demand exceeding capacity at a constrained resource than mean delay.)

The chart shows that delays are below the acceptable limits for the entire simulation. Only 42 flights have a delay of more than 1 hour and the mean delay is about 3.5 minutes. This is in line with the FAA Aviation Systems Performance Metrics (ASPM) reported mean gate-arrival delay of 5.7 minutes for this good-weather day. A very close match between ASPM data and simulation is not expected. ACES results do not include any weather effects; even on this good weather day, there were some minor weather-related delays ${ }^{[13]}$. This study does not include any off-nominal events, nor any cascading delays for consecutive flight legs flown by the same aircraft. In addition, ACES measures delay compared to an unimpeded flight, whereas ASPM reports delay compared to the airline schedule that is likely to contain additional time to allow for delays.

\section{B. 2025 Delays - Effect of Larger Aircraft and New Routes}

This section examines the delays that result from the 2025 demand, first with the same fleet mix and routes as recorded by 26 September 2006 ETMS, then with larger aircraft and new routes as explained in the "Flight Data 
Sets" section. These simulations use 2025 airport capacities, see Table 1. Sector capacities are set to twice the 2006 MAP values.

Figure 2 shows simulation results from ACES, for the 2025 max-operations scenario.

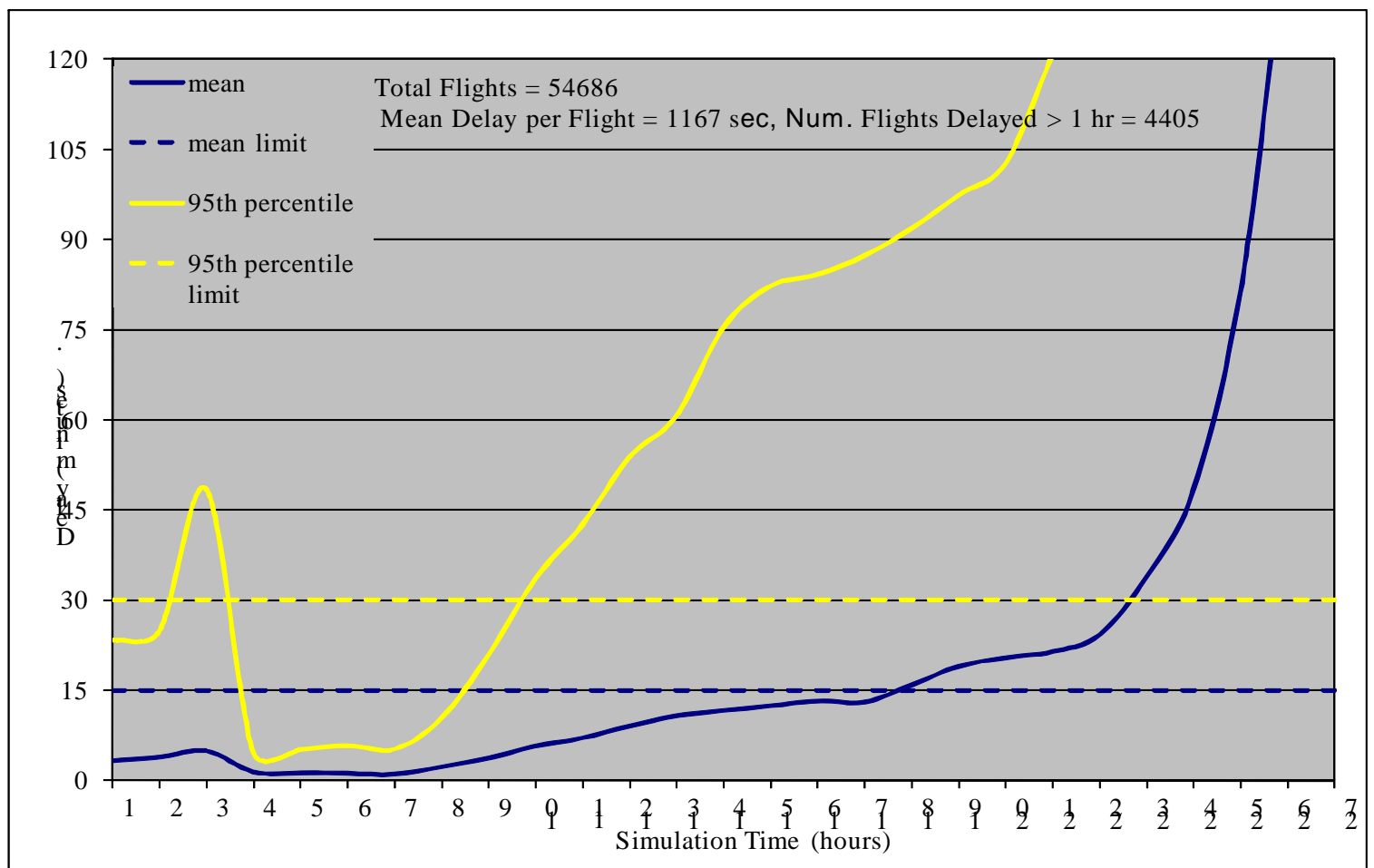

Figure 2. Commercial Passenger Flight Delays for 2025 Max-operations Scenario

This scenario has the same fleet mix and routes as the baseline day simply scaled by the increased TSAM demand. The number of flights increases by the same ratio as the increase in enplanements, a factor of 1.88, from Table 3. This is an over estimate of the expected increase in flight operations, but is included in this study for comparison.

The results show large delays; mean delay is nearly 20 minutes, with 4405 flights delayed by more than 1 hour. As the simulation progresses, delays mount up; ACES simulated Traffic Flow Management actions hold more aircraft on the ground. This scenario is infeasible with more flights scheduled in a day than can be flown in a day with the assumed NAS capacity.

Figure 3 shows results from the simulation using larger aircraft, with a limit of 40 flights each-way per day between airport-pairs, and introducing new direct routes when demand is sufficient to fill two 70-passenger aircraft per day.

A schedule frequency limit of 40 flights each-way per day is more than the maximum frequency observed in the NAS today (i.e. 37 flights each-way per day see Table 3). The total number of flights for this FDS reduces by 5252, nearly $10 \%$, compared to the max-operations scenario (see Table 2). The projected 2025 total commercial flight operations reduces to 1.70 times the baseline, compared to a factor of 1.88 for the max-operations scenario.

Mean delay is significantly reduced from nearly 20 minutes per flight to just over 8 minutes. This might appear to be acceptable, looking at the mean value alone. Closer analysis shows that delays are slowly increasing throughout the day, with the $95^{\text {th }}$ percentile exceeding the limits deemed acceptable by this study after 10 hours of simulation, and again after 21 hours of simulation. In fact, 1311 flights have a delay of more than 1 hour, affecting a large number of passengers and potentially causing missed connections.

Figure 4 shows that even with schedule frequency limits of 20 flights each-way per day between airport-pairs delays still exceed the desired limits.

For this scenario insufficient capacity at three airports, LaGuardia (LGA), Newark (EWR) and Philadelphia (PHL) is the cause of most of the delays. Table 4 shows the airport-pair routes with longest mean delays. 


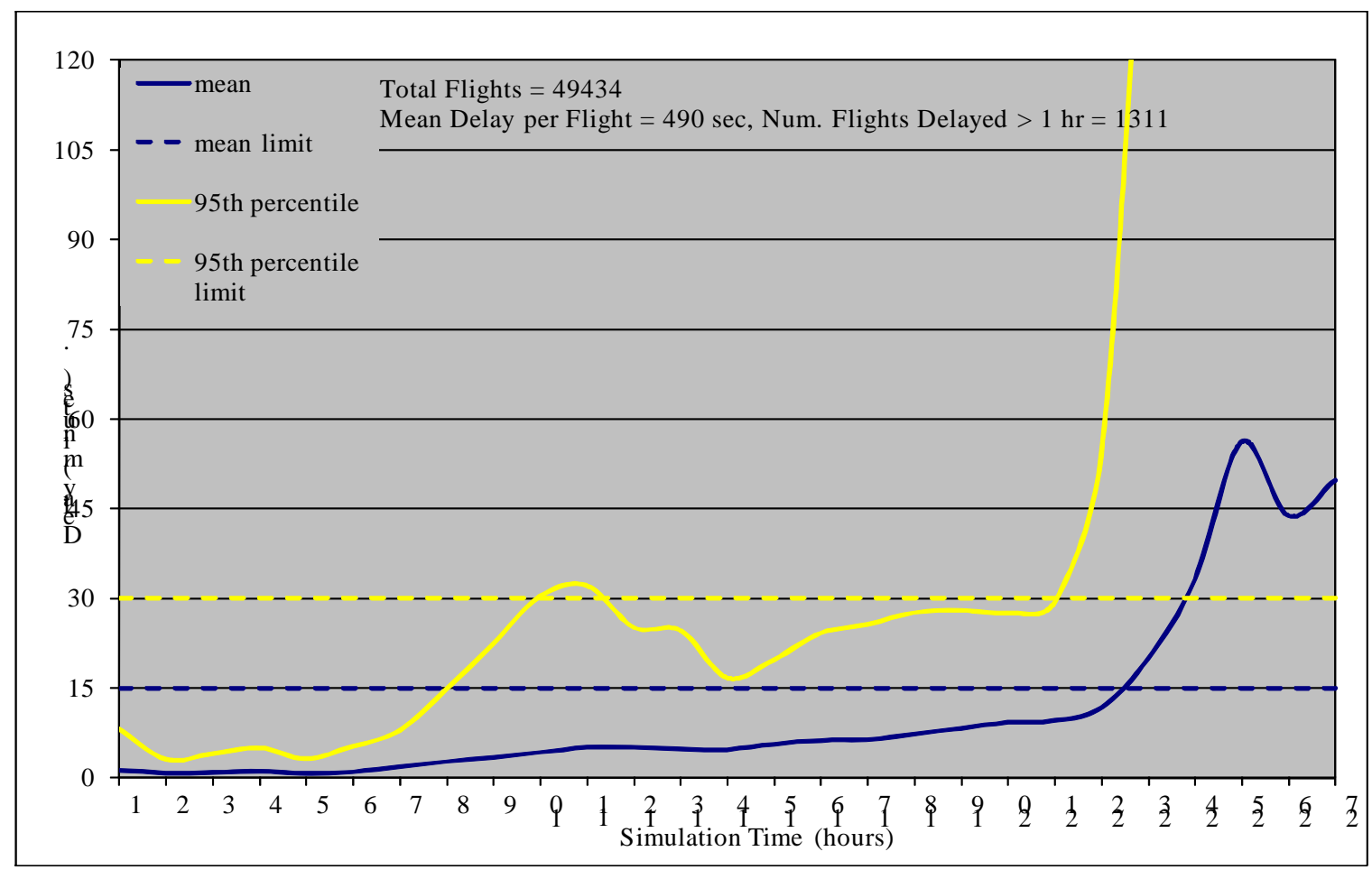

Figure 3. Commercial Passenger Flight Delays for 2025 Schedule Frequency-limit 40 Scenario

Table 4. Routes with Most Delay in 2025 for 40 Flights Schedule Frequency Limit

\begin{tabular}{ccc}
\hline Departure Airport & Arrival Airport & Mean Delay (minutes) \\
\hline \hline BOS & EWR & 106.3 \\
CLT & EWR & 103.4 \\
ATL & EWR & 96.4 \\
BOS & LGA & 164.3 \\
DCA & LGA & 138.9 \\
ORD & LGA & 136.4 \\
MCO & PHL & 111.4 \\
GSO & PHL & 110.6 \\
BOS & PHL & 79.7 \\
\hline
\end{tabular}

The delays are shorter, compared to the 40-flight schedule-frequency limit scenario, but still exceed the acceptable limits defined for this study as delay accumulates. The cause of the majority of the delays is still insufficient capacity at three airports, LGA, EWR and PHL as for the scenario with a 40-flight schedule frequency limit.

Table 5 shows the effect of a 20 flight per day limit on the routes that are most delayed with the 40 flight per day limit. Most routes show a significant reduction in delay compared to the 40-limit scenario, with the exception of BOS to EWR.

Table 5. Effect of 20 Flights Schedule Frequency Limit on 2025 Most Delayed Routes

\begin{tabular}{cccc}
\hline Departure Airport & Arrival Airport & Mean Delay (minutes) & Reduction From 40-limit scenario (minutes) \\
\hline \hline BOS & EWR & 105.58 & $0.7(1 \%)$ \\
CLT & EWR & 83.65 & $19.8(19 \%)$ \\
ATL & EWR & 80.67 & $15.7(16 \%)$ \\
BOS & LGA & 114.58 & $49.8(30 \%)$ \\
DCA & LGA & 124.52 & $14.4(10 \%)$ \\
ORD & LGA & 114.37 & $22.0(16 \%)$ \\
MCO & PHL & 77.57 & $33.8(30 \%)$ \\
GSO & PHL & 74.72 & $35.9(32 \%)$ \\
BOS & PHL & 48.37 & $31.3(39 \%)$ \\
\hline
\end{tabular}




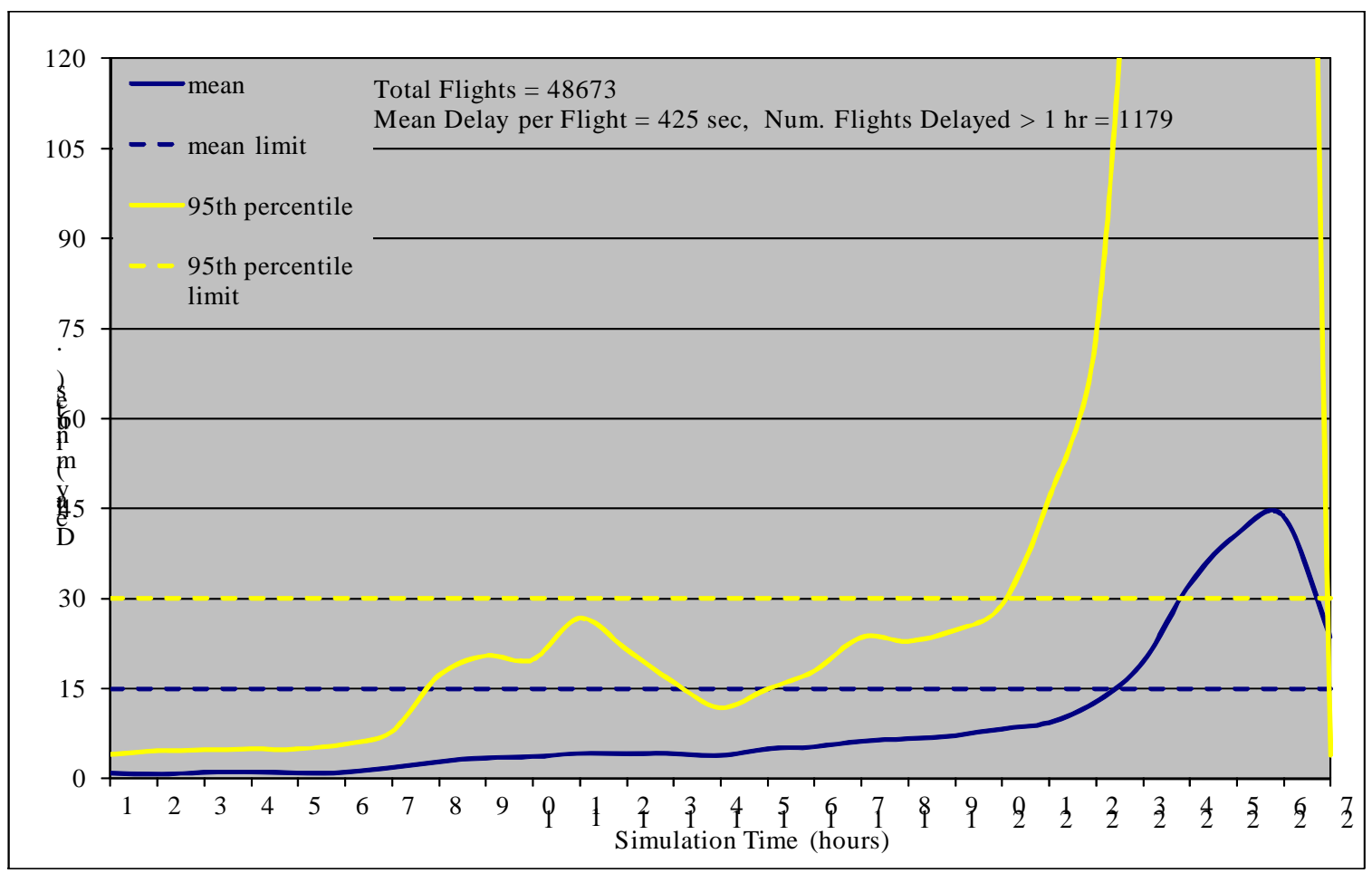

Figure 4. Commercial Passenger Flight Delays for 2025 Schedule Frequency-limit 20 Scenario

\section{2025 Delays - Effect of Increased Travel Times on Passenger Route and Transportation Mode Choice}

On some routes, delays are such that it is unlikely passengers would choose that route. Instead passengers would seek alternative airline routes, although less convenient, with less overall trip time when delays are considered, or use alternative modes of transportation where feasible. For example, DCA to LGA has a mean delay of more than 2 hours for the 2025 scenario with a 20 flight per day limit. This is in addition to the overall door-todoor commercial airline travel time of about 4 hours, giving a total trip time by airline of approximately 6 hours. It is possible to drive from DCA to LGA in 4 to 5 hours, so a proportion of the passengers may choose to travel by automobile.

TSAM can predict the effect of delays on specific routes by giving passengers the choice of alternative routes or modes. Mean delays on airport-pair routes obtained from simulation for the 20 flights schedule frequency limit scenario are input into TSAM to increase the travel-times on the congested routes.

A caveat with this approach is that when passengers move from a congested route the route becomes less congested. Some passengers will therefore move back to their original route causing an increase in delay. This cycle repeats causing an oscillation in the number of passengers on congested routes that should converge over a few iterations. In addition, the effect of airline delays on increased airline costs has not been included in this study. Assuming that the increased airline costs due to regularly occurring delays are passed on the traveler, the switch to alternate modes of transportation may be greater than indicated. Also, the effects of highway congestion and increased automobile travel times and costs are not included in this study.

The results presented in this section are for the first effect of delays only and therefore may overstate or understate the number of passengers that are likely to move from the congested routes in the equilibrium. This approach serves as a first approximation to determine the possible effects of additional route delays on the shift in demand, in terms of both a choice of mode of transportation, and choice in commercial airline route.

Figure 5 shows the effect on system-wide delays when the TSAM network uses delay-adjusted travel times. Simulation results indicate that overall delays are now much shorter on the most congested routes compared to the scenario that does not take into account passenger response to delays.

Both the mean delay and the $95^{\text {th }}$-percentile are below the desired limit for each hour of the simulation. There are only 92 flights with more than 1-hour delay; this is a better than a 10-fold reduction from the 1179 flights for the 2025 scenario that does not take into account passenger response to delay. 


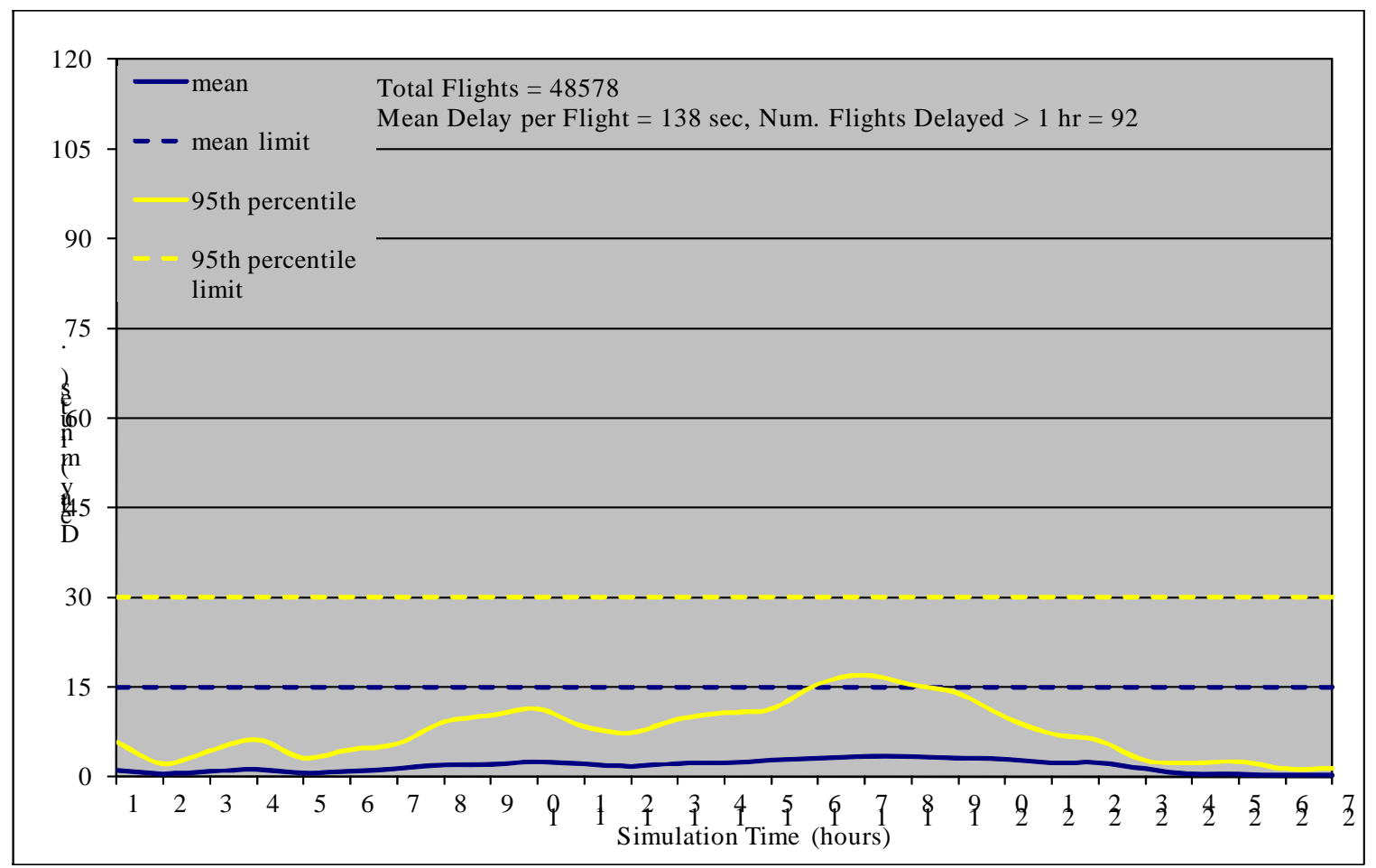

Figure 5. Commercial Passenger Flight Delays for 2025 Schedule Frequency-limit 20 Scenario with TSAM Increased Travel Times

Table 6 shows the effect of increasing the travel times used by TSAM on the routes that are most delayed. Some routes still show quite large mean delays; EWR, LGA and PHL still do not have sufficient capacity. The large reduction in delay on the congested routes compared to the 20-limit scenario supports the hypothesis that many passengers would choose alternative routes or travel by automobile if delays in the year 2025 reached the levels reported in Table 5. The results indicate that travelers are seeking alternative routes or choosing to drive, this adaptive behavior reduces overall NAS delays for the 2025-projected demand to acceptable levels. Some congestion still remains; mean delays on some PHL routes are more than 15 minutes.

Table 6. Effect of TSAM Increased Travel Times on 2025 Most Delayed Routes

\begin{tabular}{cccc}
\hline Departure Airport & Arrival Airport & Mean Delay (minutes) & Reduction From 20-limit Scenario (minutes) \\
\hline \hline BOS & EWR & 14.58 & $91.0(86 \%)$ \\
CLT & EWR & 13.30 & $70.4(84 \%)$ \\
ATL & EWR & 11.57 & $69.1(86 \%)$ \\
BOS & LGA & 12.82 & $101.8(89 \%)$ \\
DCA & LGA & 13.15 & $111.4(89 \%)$ \\
ORD & LGA & 10.85 & $103.5(91 \%)$ \\
MCO & PHL & 17.73 & $59.8(77 \%)$ \\
GSO & PHL & 19.02 & $55.7(75 \%)$ \\
BOS & PHL & 19.95 & $28.4(59 \%)$ \\
\hline
\end{tabular}

Table 7 shows the reduction in total operations at the most congested airports in 2025 caused by passengers avoiding airports with severe delays. The $13 \%$ to $15 \%$ reduction in operations at these airports explains the large reduction in delay determined by simulation.

Table 7. Total Operations per Day at Most Delayed Airports in 2025

\begin{tabular}{ccccc}
\hline \multirow{2}{*}{ Airport } & $\begin{array}{c}\text { 40-limit } \\
\text { Scenario }\end{array}$ & $\begin{array}{c}\text { 20-limit } \\
\text { Scenario }\end{array}$ & $\begin{array}{c}\text { 20-limit TSAM Increased } \\
\text { Travel Times Scenario }\end{array}$ & $\begin{array}{c}\text { Reduction From 20-limit } \\
\text { scenario }\end{array}$ \\
\hline \hline EWR & 1615 & 1594 & 1347 & $247(15 \%)$ \\
LGA & 1629 & 1567 & 1345 & $223(14 \%)$ \\
PHL & 1926 & 1885 & 1641 & $244(13 \%)$ \\
\hline
\end{tabular}




\section{Passenger Travel Time, Distance Penalty and Analysis of Fuel Usage}

The large reduction in the 2025 air transportation system delays that results when passengers choose to avoid congested routes has a cost. Some passengers do not travel using their first choice of air-route or may choose to travel by automobile to avoid delays. This second-choice trip must result in a penalty compared to using the first choice; this could be increased travel-time, an increase in distance travelled or both, compared to the first-choice airroute without the additional congestion.

TSAM does not track individual passengers through the system; rather, TSAM aggregates flows of passengers to county-to-county trips, county-to-airport trips, and then to airline flight routes. This makes it difficult to compare individual passenger route choices between two demand scenarios. Particularly, when analyzing the change in demand on a single airport-to-airport route it is not possible to determine how much of this change was due to the delays on this route and how much was due to nearby or alternate routes. Also, county-to-airport demand is not attributed to a specific airline route, thus, if the demand changes, it is also not possible to identify which route or routes caused this change. Instead, the analysis must compare aggregate numbers of commercial airline and automobile trips to determine the overall effects of passenger choice.

Table 8 shows the aggregate effect of delays on passenger choice of airline-trips and automotive-trips.

Table 8. Origin-to-Destination Total Trip Distance, Time, and Fuel Used*

\begin{tabular}{|c|c|c|c|c|c|c|}
\hline \multirow[b]{2}{*}{ Parameter } & \multicolumn{3}{|c|}{ First Choice } & \multicolumn{3}{|c|}{ Second Choice } \\
\hline & $\begin{array}{c}\text { Commercial } \\
\text { Airline }\end{array}$ & Automobile & Total & $\begin{array}{c}\text { Commercial. } \\
\text { Airline } \\
\text { (difference) } \\
\end{array}$ & $\begin{array}{l}\text { Automobile } \\
\text { (difference) }\end{array}$ & $\begin{array}{c}\text { Total } \\
\text { (difference) }\end{array}$ \\
\hline $\begin{array}{l}\text { Person Trips } \\
\text { per Day }\end{array}$ & $1,876,012$ & $7,982,068$ & $9,858,080$ & $\begin{array}{l}1,860,414 \\
\mathbf{( - 1 5 , 5 9 8 )} \\
(\mathbf{- 0 . 8 3 \% )}\end{array}$ & $\begin{array}{c}7,997,666 \\
\mathbf{( 1 5 , 5 9 8 )} \\
\mathbf{( 0 . 2 \% )}\end{array}$ & $\begin{array}{c}9,858,080 \\
\mathbf{( 0 )} \\
\mathbf{( 0 \% )}\end{array}$ \\
\hline $\begin{array}{c}\text { Distance } \\
\text { (person } \mathbf{n m})\end{array}$ & $1,704,625,188$ & $1,734,402,440$ & $3,439,027,628$ & $\begin{array}{c}1,697,162,732 \\
\mathbf{( - 7 , 4 6 2 , 4 5 6 )} \\
\mathbf{( - 0 . 4 4 \% )}\end{array}$ & $\begin{array}{c}1,741,043,782 \\
\mathbf{( 6 , 6 4 1 , 3 4 2 )} \\
\mathbf{( 0 . 3 8 \% )}\end{array}$ & $\begin{array}{c}3,438,206,514 \\
\mathbf{( - 8 2 1 , 1 1 4 )} \\
\mathbf{( - 0 . 0 2 \% )}\end{array}$ \\
\hline $\begin{array}{l}\text { Time (person } \\
\text { hours) }\end{array}$ & $18,454,878$ & $40,639,859$ & $59,094,737$ & $\begin{array}{c}18,493,447 \\
\mathbf{( 3 8 , 5 6 9 )} \\
\mathbf{( 0 . 2 1 \% )}\end{array}$ & $\begin{array}{c}40,838,221 \\
\mathbf{( 1 9 8 , 3 6 2 )} \\
(\mathbf{0 . 4 9 \% )}\end{array}$ & $\begin{array}{c}59,331,668 \\
\mathbf{( 2 3 6 , 9 3 1 )} \\
(\mathbf{0 . 4 0 \% )}\end{array}$ \\
\hline $\begin{array}{l}\text { Total Fuel } \\
\text { Used }^{*} \\
\text { (U.S. Gal.) }\end{array}$ & $83,312,848$ & $58,703,373$ & $142,016,221$ & $\begin{array}{c}82,115,735 \\
(-\mathbf{1}, \mathbf{1 9 7 , 1 1 3}) \\
\mathbf{( - 1 . 4 4 \% )}\end{array}$ & $\begin{array}{c}58,928,159 \\
(224,786) \\
(\mathbf{0 . 3 8 \% )}\end{array}$ & $\begin{array}{c}141,043,894 \\
(-\mathbf{9 7 2 , 3 2 7 )} \\
\mathbf{( - 0 . 6 8 \% )}\end{array}$ \\
\hline
\end{tabular}

* Total Fuel Used assumes $6.79 \mathrm{lbs} /$ gallon for commercial-air and 20-statute m.p.g. and 1.7 trip passengers per automobile.

The first choice trips are those taken if travel times are unimpeded by delays. The second choice trips are those that passengers take when congestion delays make their first choice unacceptable or less attractive compared to automobile. A reduction in the daily number of airline trips by 15,598 and a corresponding increase in the number of trips by automobile is observed.

Although this is only a $0.8 \%$ decrease in airline trips, these are trips on the most congested routes and have a significant beneficial effect on reducing airline route congestion. The results of this study do not take into account the effect of additional congestion on highways. This may reduce the time advantage and hence the results may overstate the number of travelers that would choose to change their travel plans from airline to automobile.

There is a slight decrease in total origin to destination travel distance of $821,114 \mathrm{~nm}$; this is a negligible $0.02 \%$ decrease. There is no distance penalty associated with the second-choice scenario.

There is an increase in total origin to destination travel time of 236,931 hours; this is a $0.4 \%$ increase. The time penalty associated with the second-choice scenario is a $0.4 \%$ increase in trip time.

The changes in passenger route choice and transportation mode have an impact on fuel usage. An estimate of fuel usage indicates that moving some trips to automobile uses less total fuel. The automobile fuel estimate assumes 1.7 passengers per automobile (based on the 1995 ATS average ${ }^{[6]}$ ) and an efficiency of 20-statute m.p.g. The airline fuel-usage data are from the ACES simulation results, which uses Eurocontrol's Base of Aircraft DAta ${ }^{[15]}$ (BADA) aircraft performance data. The increase in automobile fuel used, 224,786 gallons, is more than offset by the saving of 1,197,113 gallons by commercial-air. The reduction in fuel consumed by commercial air is due to both the reduced number of flights and the substantial reduction in delay to the remaining flights. 
In summary, there is a $0.4 \%$ penalty overall to long-distance travel times compared to unimpeded travel times when passengers choose to avoid congested airline-routes. This is the cost associated with passengers using their second choice of airline route or choosing to travel by automobile. There is not any distance penalty and there is a small advantage in reduced fuel usage.

\section{Conclusions}

A significant finding of this study is that the adaptive behavior of passengers to avoid congested airline-routes is an important factor when projecting demand for transportation systems. TSAM projects that passengers will seek alternative airline routes where available and will choose to travel by automobile for shorter trips. This causes a large reduction in delays on the congested routes and an overall reduction in delay to the air-transportation network.

This reduction in delays for the most-delayed passengers has a cost. Total system-wide origin-to-destination travel time increases by $0.4 \%$ and some of the delayed passengers are inconvenienced to the extent that they abandon their first choice of route or transportation mode. Relying on the adaptive behavior of passengers is not a solution to the capacity problem. The increase in total travel time is undesirable, the avoidance of long delays by the most delayed passengers leads to a small overall increase in trip times. It is clearly preferable to have sufficient capacity to meet demand. If sufficient capacity cannot be achieved at a few airports, adaptive behavior of passengers will likely lead to a system that functions without very large system-wide average delays in ideal weather.

The ACES simulation results from this study determined that:

- NextGen Operational Improvements alone, using the estimated capacity-benefit values, do not provide sufficient airport capacity to meet the projected demand for passenger air transportation in 2025 without significant system delays.

- Using larger aircraft with more seats on high-demand routes and introducing new direct routes, where demand warrants, significantly reduces delays, complementing NextGen improvements. This still does not reduce delays to acceptable levels on some routes.

- Alternative air routes are available avoiding congested routes and, for some shorter trips, passengers will choose to drive, reducing delays on most routes to acceptable levels for the 2025 scenario. Mean delay per flight from simulation, is less than three minutes for this second-choice scenario; this is similar to the 2006 baseline scenario mean delay. The penalty is that the alternative routes and option to drive increases overall trip time by $0.4 \%$ and may be less convenient than the first-choice route, if that first choice had sufficient capacity.

The results rely on transportation demand projections from TSAM for the year 2025 and estimates of the increased airport capacity that may be available, due to both NGIP 2018 and NextGen 2025 improvements. Results are for perfect weather, Visual Meteorological Conditions.

\section{References}

1.Joint Planning and Development Office, Concept of Operations for the Next Generation Air Transportation System, Version 2.0, 13 June 2007

2.JPDO Integrated Work Plan, Version 1.0, 30 September 2008

3.Federal Aviation Administration, Terminal Area Forecast Summary, Fiscal Years 2009-2030, Updated 2/2/2010.

4.Viken, J., et. al., "Utilizing Traveler Demand Modeling to Predict Future Commercial Flight Schedules in the NAS," $11^{\text {th }}$ AIAA/ISSMO Multidisciplinary Analysis and Optimization Conference, September 2006, Portsmouth, Virginia.

5.Woods and Poole Complete Economic and Demographic Data Source, accessed 20 April 2010 http://www.woodsandpoole.com

6.ATS, American Travel Survey, Bureau of Transportation Statistics, , accessed 18 June 2010, http://www.bts.gov/publications/1995_american_travel_survey/index.html

7.Official Airline Guide, accessed 18 June 2010, http://www.oag.com

8.Airline Origin and Destination Survey, accessed 29 June 2010, http://www.transtats.bts.gov

9.NASA contract number NNA05BE01C, Contract Data Requirements List 17.3, “Airspace Concept Evaluation System (ACES) Software User Manual", Jan. 2009.

10.Metrics for the NASA Airspace Systems Program, Smith, Jeremy C. , Neitzke, Kurt W, Langley Research Center, Hampton, Virginia, September 2009, NASA/SP-2009-6115

11.Modeling and Simulation for Assessing NextGen Midterm Performance, Optimal Synthesis Inc., May 2009, OSS-080502

12.Advanced Vehicle Concepts and Implications for NextGen, Sensis Corporation, November 2009, NASA/CR-2009000000

13.Cluster Analysis for the Annualization of ACES Simulated NAS Metrics, Metron Aviation, 31 January 2009

14.Airbus Global Market Forecast, accessed 20 April 2010, 
http://www.airbus.com/en/myairbus/global_market_forcast.html

15.Base of Aircraft DAta (BADA), Eurocontrol Aircraft Performance Model, accessed 18 June 2010, http://www.eurocontrol.int/eec/public/standard_page/proj_BADA.html 